\title{
The Use of Gigantochloa Bamboo-Derived Biochar for the Removal of Methylene Blue from Aqueous Solution
}

\author{
Nabilah Suhaimi, ${ }^{1}$ Muhammad Raziq Rahimi Kooh $(\mathbb{D}),{ }^{1}$ Chee Ming Lim $\left(\mathbb{D},{ }^{1}\right.$ \\ Chung-Ting Chou Chao ${ }^{D}{ }^{2}$ Yuan-Fong Chou Chau ${ }^{1},{ }^{1}$ Abdul Hanif Mahadi $\mathbb{D}^{1},{ }^{1}$ \\ Hai-Pang Chiang $\mathbb{D}^{2}{ }^{2}$ Nurul Hazimah Haji Hassan, ${ }^{1}$ and Roshan Thotagamuge $\mathbb{D}^{1,3}$ \\ ${ }^{1}$ Centre of Advance Material and Energy Sciences, Universiti Brunei Darussalam, Jalan Tungku Link, \\ Gadong BE1410, Brunei Darussalam \\ ${ }^{2}$ Department of Optoelectronics and Materials Technology, National Taiwan Ocean University, Keelung 20224, Taiwan \\ ${ }^{3}$ Department of Nano Science Technology, Faculty of Technology, Wayamba University of Sri Lanka, Kuliyapitiya 60200, Sri Lanka
}

Correspondence should be addressed to Muhammad Raziq Rahimi Kooh; raziq.kooh@ubd.edu.bn and Roshan Thotagamuge; roshan@wyb.ac.lk

Received 8 January 2022; Revised 25 January 2022; Accepted 2 February 2022; Published 14 February 2022

Academic Editor: Selvaraju Narayanasamy

Copyright (c) 2022 Nabilah Suhaimi et al. This is an open access article distributed under the Creative Commons Attribution License, which permits unrestricted use, distribution, and reproduction in any medium, provided the original work is properly cited.

\begin{abstract}
In this study, locally grown bamboo (Gigantochloa spp.) was used as feedstock for pyrolysis production of biochar under various pyrolysis temperatures $\left(400-800^{\circ} \mathrm{C}\right)$. The resultant biochars were tested for their performance in adsorptive removal of the methylene blue (MB) dye. The scope of the adsorption experiment includes the effects of adsorbent dosage, solution $\mathrm{pH}$, initial adsorbate concentration, and contact time. The adsorption data confirmed that pyrolysis temperature has a significant effect on adsorptive performance, whereas biochar pyrolysed at $500^{\circ} \mathrm{C}(\mathrm{BC} 500)$ has the highest adsorptive performance with the maximum adsorption capacity (derived from the Langmuir model) being $86.6 \mathrm{mg} \mathrm{g}^{-1}$. Basic characterisations (SEM, EDX, XRD, FTIR, and BET) were carried out for BC500 where FTIR and SEM confirmed the adsorption of MB onto the biochar, while the BET data showed the reduction of the BET surface area, total pore volume, and pore diameter after the adsorption process.
\end{abstract}

\section{Introduction}

The textile industry is an ever-growing market associated with the production of fabric. Despite its significance, this industrial sector contributes to the largest global polluters, particularly in releasing untreated effluents into the water bodies $[1,2]$. These effluents consist of various organic compounds and toxic substances. When not adequately treated, they can not only degrade the environment but also degrade the health of humans and animals [2-5]. Dyes, which are widely used to impart colour onto products, are among the many effluents that are discharged from textile factories, which account for more than $50 \%$ of the world's dyestuff market [6]. Methylene blue (MB) is an example of a commonly used basic dye for dying wool, cotton, and silk [7]. Despite its many practical uses, $\mathrm{MB}$ is a known irritant that can cause eye burn and, if consumed, can cause nausea, headache, increased heart rate, and the inflammation of the gastrointestinal tracts [7-9].

There are many dye wastewater treatment methods such as chemical precipitation, adsorption, ion exchange, membrane technologies, electrodialysis, phytoremediation, and photocatalysis [10-15]. Adsorption is one of the popular wastewater remediation techniques due to its efficiency, simplicity, and low cost [16-20] and does not result in sludge production [21]. In addition, one of its major benefits is its eco-friendly features as its adsorbents can potentially be recovered and recycled [13, 22-24].

Activated carbon has undoubtedly been a conventional adsorbent in wastewater treatment universally $[25,26]$. However, despite its prolific use, some drawbacks are its high cost and the dependency of complexing agents, which 
lead researchers to find a more suitable alternative [27]. Some low-cost and readily available adsorbents include natural materials such as biochar, zeolites, clay, or certain waste products from industrial operations such as fly ash and reused sanding wastes $[14,28,29]$. Biochar has been a popular choice among researchers due to its specific properties, including large specific surface area, porous structure, enriched surface functional groups, and mineral components, making it suitable as an adsorbent for wastewater remediation [30].

Bamboo is one of the many applicable biomasses with many benefits as feedstock for making biochar. They are found abundantly in natural habitats, especially in Asia and the tropical regions, due to their fast proliferative growth. Most bamboo species take only a few months to grow to full size and are among the fastest-growing plants [31]. Bamboo is also considered a renewable biomass resource. Bamboo is rich in lignocellulosic content, which plays a significant role in becoming an excellent raw material for biochar production [27, 32-34].

Regardless of the increasing published literature, more input is required to ensure an effluent clean-up as numerous factors affect this adsorption ability. From literature, it is known that altering pyrolysis conditions, particularly the pyrolysis temperature, can significantly impact the properties of the biochar. The biochar properties such as its elemental composition, physical structure, surface functional groups, surface area, pore size, and stability can influence the level of the adsorption capacity $[35,36]$. In general, high pyrolysis temperature can increase the surface area and porosity of the adsorbent while keeping the minerals such as potassium, phosphorus, and calcium in the biochar. These minerals are known to enhance the adsorption capacity [37-39]. However, at high pyrolysis temperature, the functional groups such as carboxyl, hydroxyl, and amino groups on the surface of adsorbents may decrease, resulting in the reduced capacity of adsorption [37, 40]. According to Sun et al., the pyrolysis temperature and feedstock are responsible for the production rate, thermal stability, carbon content, and element composition of biochar [39]. Sizirici et al. showed that higher pyrolysis temperature resulted in biochar with lower adsorptive performance than those obtained at a lower temperature [37]. Another study shows the impact of pyrolysis temperature on lead adsorption and revealed that $550^{\circ} \mathrm{C}$ is the optimal temperature of making biochar for lead adsorption [41]. Primary cracking, secondary decomposition, and the formation of oxygen functional groups start around $400-500^{\circ} \mathrm{C}$ during pyrolysis. Hence, biochar samples produced within the temperature range of $500-700^{\circ} \mathrm{C}$ show better reactivity and adsorption behaviour than biochar samples produced below or above that temperature [42]. Those studies evidence that the adsorption mechanism and performance are highly affected by complex properties of biochar which are mainly based on the type of biomass and pyrolysis temperature [37-41].

In this paper, biochar prepared from locally grown Gigantochloa bamboo was employed to remove MB dye. The specific objectives were to optimise the pyrolysis temperature for the production of biochar to achieve the high
TABLE 1: Yield of biochar at different pyrolysis temperatures.

\begin{tabular}{lc}
\hline Sample & Biochar yield (\%) \\
\hline BC400 & 4.85 \\
BC500 & 11.39 \\
BC600 & 8.12 \\
BC700 & 3.87 \\
BC800 & 3.44 \\
\hline
\end{tabular}

adsorption capacity. With the obtained temperature, adsorption conditions were optimised for efficient removal of dye, including adsorbent dosage, initial concentration, $\mathrm{pH}$, and contact time. Further, the prepared biochar was characterised using Brunauer-Emmett-Teller (BET), Fourier transform infrared (FTIR), scanning electron microscope (SEM), and energy-dispersive X-ray spectroscopy (EDX). Lastly, the adsorption behaviour was modelled using various isotherm and kinetic models.

\section{Methodology}

2.1. Preparation of Adsorbent. The Gigantochloa bamboo stems were obtained locally from Kampong Kianggeh, Brunei-Muara District, Brunei Darussalam. The surface of the bamboo was washed and sun-dried, and the outer layer was peeled. They were then further dried in a drying oven at a temperature of $\sim 80^{\circ} \mathrm{C}$ for a few days until there was no further noticeable decrease in weight.

The dried bamboo from the oven was directly transferred to the muffle furnace, where they undergo pyrolysis. The bamboo was divided into five groups, and each group was pyrolysed at different temperatures $(400,500,600,700$, and $800^{\circ} \mathrm{C}$ ). The heating rate was set at $10^{\circ} \mathrm{C} \mathrm{min}^{-1}$ and with $4 \mathrm{~h}$ of holding time upon reaching the desired temperatures. The flow rate of $\mathrm{N}_{2}$ was at a constant $20 \mathrm{~mL} \mathrm{~min}^{-1}$ throughout the pyrolysis process. After the furnace temperature reached room temperature, the biochar was taken out from the furnace. It was ground using pestle and mortar and passed through $150 \mu \mathrm{m}$ mesh sieves and stored in its respective airtight container. BC400, BC500, BC600, BC700, and BC800 were used to represent the biochar derived at different temperatures at $400,500,600,700$, and $800^{\circ} \mathrm{C}$, respectively.

The yield of biochar was calculated according to

$$
\text { Biochar yield }(\%)=\frac{\text { Mass of biochar }}{\text { Mass of bamboo }} \times 100 \text {. }
$$

2.2. Chemical Reagents. The MB powder was purchased from Merck, Germany (dye purity 95\%, reagent grade). The MB stock solution was prepared by dissolving the MB powder in distilled water, and all other concentrations were obtained via serial dilution. All other chemicals used in this study are of reagent grade and used as received without purification.

\subsection{Batch Adsorption Experiments}

2.3.1. Screening Test. After pyrolysis, $0.04 \mathrm{~g}$ from each biochar sample was mixed with $20 \mathrm{~mL}$ of $\mathrm{MB}$ dye. The solution was shaken for $3 \mathrm{~h}$ at a speed of $200 \mathrm{rpm}$ with an orbital 


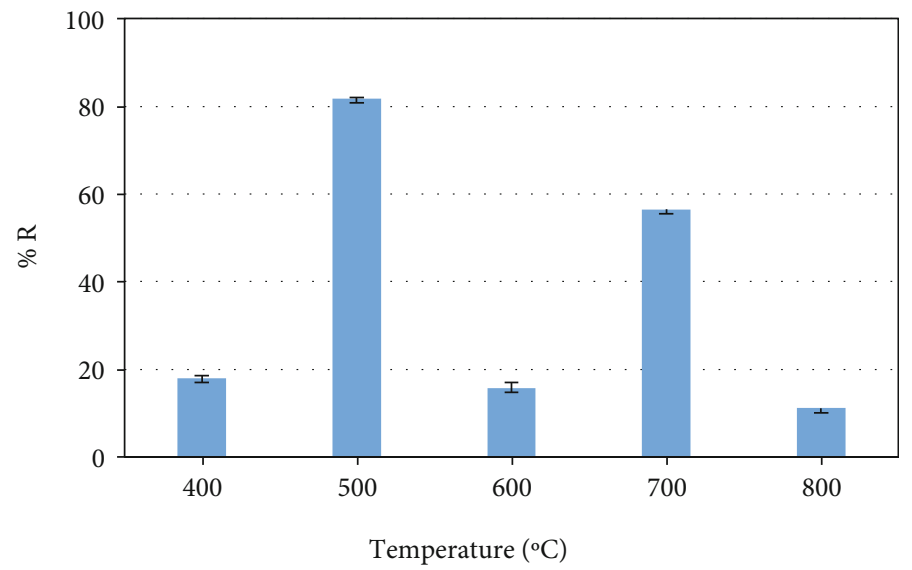

FIGURE 1: The performance of biochar produced by various pyrolysis temperatures on removing MB dye from solution (room temperature, unadjusted $\mathrm{pH}, C_{i}=100 \mathrm{ppm}$, and contact time of $3 \mathrm{~h}$ ).

shaker (MIULab GS-20). The purpose of this method was to find the most efficient adsorption process according to their pyrolysis temperature. With the optimum sample, it was then made to be the constant variable for the proceeding experiment.

2.3.2. Adsorbent Dosage, Initial Concentration of Solution, $\mathrm{pH}$, and Contact Time. The general procedure for all adsorbent dosage, initial dye concentration, $\mathrm{pH}$, and contact time studies involves shaking the known weight of adsorbent in $20 \mathrm{~mL}$ of known concentration of $\mathrm{MB}$ with an orbital shaker for $3 \mathrm{~h}$ and at agitating speed of $200 \mathrm{rpm}$ at room temperature. The mixture was filtered, and the filtrate was measured using a UV-vis-NIR spectrometer (Agilent technologies, Cary 5000, US) at an absorbance $\left(\lambda_{\max }\right)$ of $664 \mathrm{~nm} . q_{e}$ and percentage removal were calculated using equations (2) and (3), respectively. The effects of adsorbent dosage (0.01-0.06 g), $\mathrm{pH}(2-10)$, initial dye concentration $\left(20-400 \mathrm{mg} \mathrm{L}^{-1}\right)$, and contact time (5-180 min) were investigated. To increase accuracy of the data, each experiment was done twice, and the average was taken.

$$
\begin{array}{r}
q_{e}=\frac{C_{i}-C_{e}}{m} \times V, \\
\% R=\frac{C_{i}-C_{e}}{C_{i}} \times 100,
\end{array}
$$

where $C_{i}\left(\mathrm{mg} \mathrm{L}^{-1}\right)$ is the initial concentration of the solution, $m(\mathrm{~g})$ is the mass of adsorbent used, and $V(\mathrm{~L})$ is the volume of dye used.

2.3.3. Optimisation of Adsorption Conditions. Optimising the adsorption parameters is equally crucial as the pyrolysis temperature for biochar. These are several parameters (effects of adsorbent dosage, initial adsorbate concentration, solution $\mathrm{pH}$, and contact time) that are essential in a typical adsorption study [43]. In general, increasing adsorbent dosage allows higher availability of adsorption sites for interaction with the adsorbates. However, when dosage exceeds a certain level, this leads to a plateau in adsorptive performance. This is due to the collision of adsorbent particles
TABLE 2: Effect of temperature on the specific surface area of biochar.

\begin{tabular}{lccc}
\hline Sample & $S_{\text {BET }}\left(\mathrm{m}^{2} \mathrm{~g}^{-1}\right)$ & $V_{\text {TOTAL }}\left(\mathrm{cm}^{3} \mathrm{~g}^{-1}\right)$ & $D_{p}(\mathrm{~nm})$ \\
\hline BC400 & 28.4270 & 0.032109 & 5.00934 \\
BC500 & 4.1519 & 0.015165 & 14.61015 \\
BC600 & 10.6617 & 0.020640 & 7.74367 \\
BC700 & 8.3130 & 0.017765 & 8.54812 \\
BC800 & 8.9699 & 0.019398 & 8.65043 \\
\hline
\end{tabular}

and thus overlapping of the adsorption sites [44]. The initial adsorbate concentration typically results in increased adsorptive performance at higher adsorbate concentration due to the higher driving force caused by the concentration gradient according to Fick's law of diffusion. Similar to adsorbent dosage, the adsorptive performance becomes plateau at a particular level of adsorbate concentration due to the exhaustion of adsorption sites. The solution $\mathrm{pH}$ controls the electrostatic interaction between the functional groups on the adsorbent's surface and the adsorbate [45]. Lastly, the contact time is the duration the adsorbent is in contact with the adsorbate and is essential to confirm the adsorption process has reached equilibrium [46, 47].

2.3.4. Proper Disposal of Generated Wastes. All generated wastes were collected and are handled by a waste disposal company, specialised in the proper disposal of chemical wastes.

2.4. Biochar Characterisations. In this study, SEM, EDX, $\mathrm{XRD}, \mathrm{FTIR}$, and BET were used for characterising the biochar. The surface morphology and surface element analysis of BC500 before and after adsorption was characterised using a FE-SEM (JEOL JSM-7600F) equipped with an EDX spectrometer. An accelerating voltage of $10 \mathrm{kV}$ with a working distance of $9-16 \mathrm{~mm}$ was maintained during the analysis. These analyses provide important visual insights as well as the information about the elemental composition of the adsorbent's surface. A Shimadzu X-ray diffractometer (XRD-7000) with $\mathrm{Cu} \mathrm{K} \alpha$ radiation source $(\lambda=1.54060 \AA)$ at $2 \theta$ range between 20 and $80^{\circ}$ and a sampling rate of $5^{\circ} \mathrm{min}^{-1}$ 


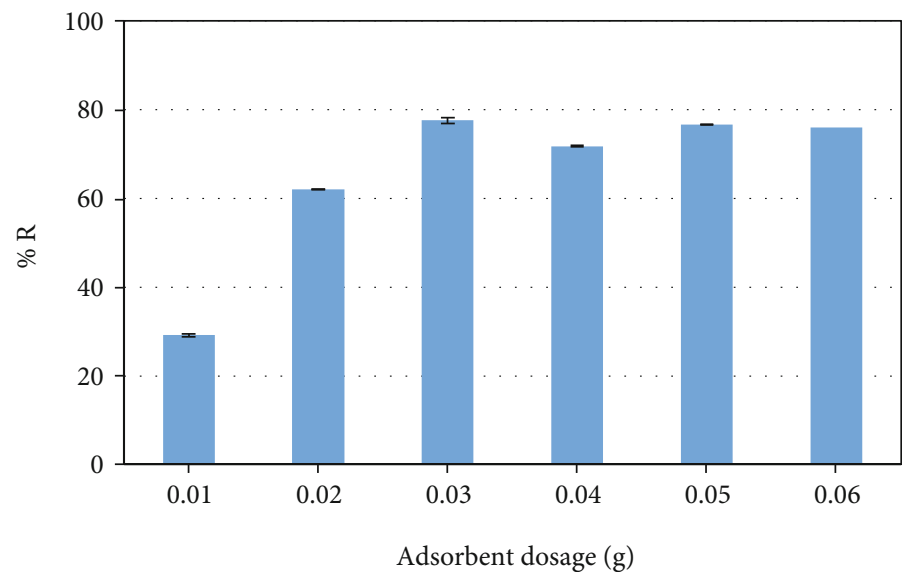

FIgURE 2: The effect of adsorbent dosage on removing MB dye from solution using BC500 (room temperature, unadjusted $\mathrm{pH}, C_{i}=100 \mathrm{ppm}$, and contact time $=3 \mathrm{~h}$ ).

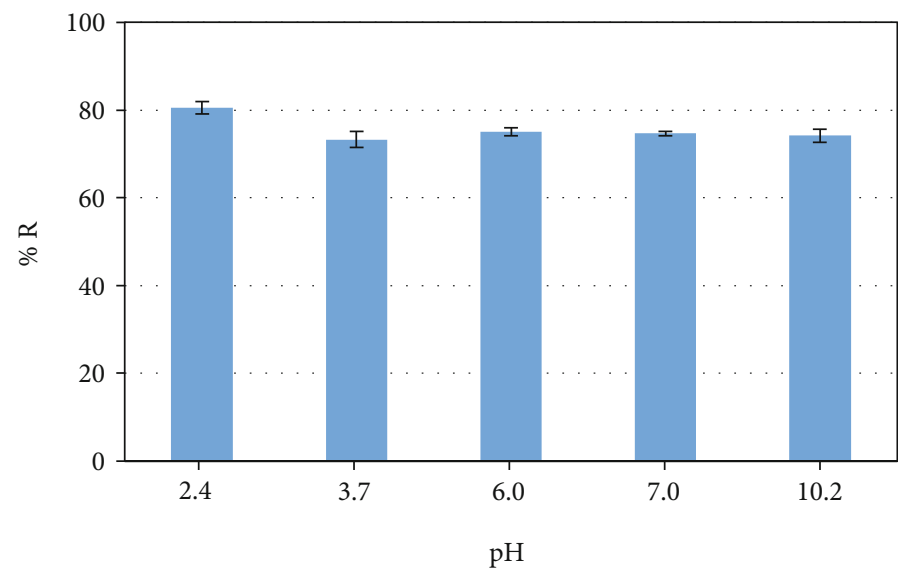

Figure 3: The effect of $\mathrm{pH}$ on removing $\mathrm{MB}$ dye from solution using $\mathrm{BC} 500$ (room temperature, $C_{i}=100 \mathrm{ppm}$, and contact time $=3 \mathrm{~h}$ ).

was used to determine the XRD pattern of biochar before and after adsorption. The XRD data provides important information about the crystalline structure. A FTIR spectrometer was used to determine the functional groups of biochar involved before and after reacting with $\mathrm{MB}$ dye, and FTIR was carried out using an Agilent Cary 630 FTIR spectrometer with $400-4000 \mathrm{~cm}^{-1}$ wavelength range at a resolution of $8 \mathrm{~cm}^{-1}$, recording 32 scans per sample. The data derived from FTIR spectra is important for determining the functional group involved in the adsorption process. The biochar's BET surface area, total pore volume, and pore diameter were determined using the Micrometrics ASAP 2020 surface area and porosity analyser (USA), under nitrogen-adsorption desorption isotherm at $77 \mathrm{~K}$.

2.5. Adsorption Kinetic Modelling. The adsorption kinetics of adsorbate onto biochar was studied using the pseudo-firstorder, pseudo-second-order, and Weber-Morris kinetic models.

This pseudo-first-order model describes the relationship between the sorption sites of the adsorbents and adsorbates [48]. The equation in its linear form is given by

$$
\log \left(q_{e}-q_{t}\right)=\log q_{e}-\frac{t}{2.303} k_{1}
$$

where $q_{e}$ and $q_{t}$ are the amounts of adsorbate adsorbed at equilibrium and at time $t(\mathrm{~min})$, respectively, and $k_{1}$ is the rate constant of adsorption $\left(\mathrm{min}^{-1}\right)$. The linear plot of $\mathrm{ln}$ $\left(q_{e}-q_{t}\right)$ against time was used to determine the rate constant $k_{1}\left(\mathrm{mgg}^{-1}\right)$.

The pseudo-second-order model focuses more on the chemisorption process and the dependency of the adsorption capacity on time [49]. This can be determined based on equation (5) expressed as

$$
\frac{t}{q_{t}}=\frac{1}{q_{e}^{2} k_{2}}+\frac{t}{q_{e}} .
$$

The linear plot of $t / q_{t}$ against $t$ was plotted to determine the pseudo-second-order rate constant, $k_{2}\left(\mathrm{~g} \mathrm{mg}^{-1} \mathrm{~min}^{-1}\right)$.

Weber-Morris is a suitable model when the internal surface or pore diffusion of pollutant inside the sorbent is the 


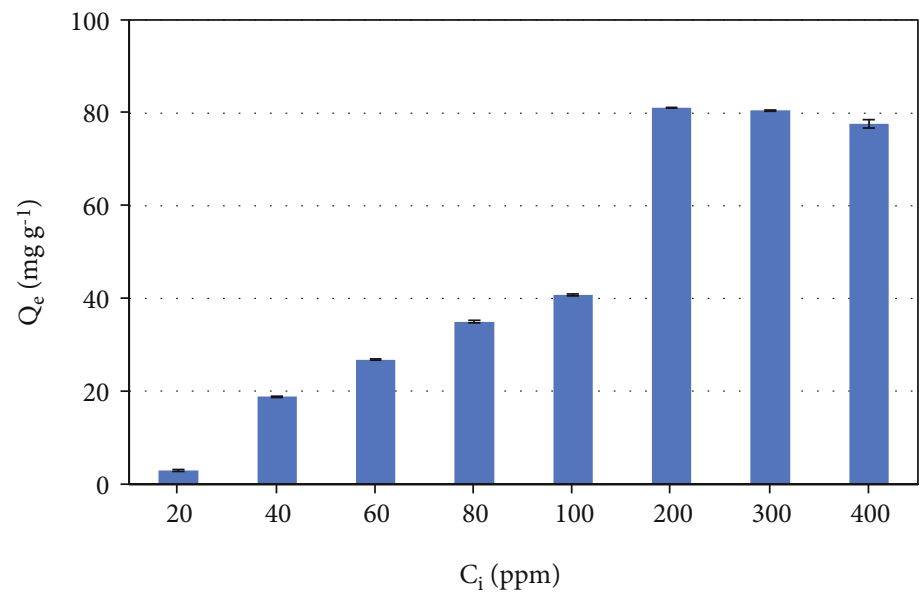

Figure 4: The effect of initial dye concentration on removing MB from solution using BC500 (room temperature, unadjusted pH, and contact time $=3 \mathrm{~h}$ ).

rate-limiting step. Equation (6) shows the Weber-Morris model.

$$
q_{t}=k_{3} t^{1 / 2}+C
$$

$k_{3}\left(\mathrm{mgg}^{-1} \mathrm{~min}^{-1 / 2}\right)$ is the intraparticle diffusion rate constant which can be determined by plotting linear graph of $q_{t}$ against $t^{1 / 2}$.

2.6. Adsorption Isotherm. To illustrate the mechanism of distribution of the adsorption molecules between the liquid and solid phases when the adsorption process reaches the equilibrium state, several adsorption isotherm (Langmuir, Freundlich, Temkin, and Dubinin-Radushkevich (D-R)) models were used.

The Langmuir model describes the monolayer sorption on apparently localised adsorption sites [50]. The linearised form of the Langmuir isotherm is expressed as

$$
\frac{C_{e}}{q_{e}}=\frac{1}{K_{\mathrm{L}} q_{m}}+\frac{C_{e}}{q_{m}},
$$

where $C_{e}\left(\mathrm{mg} \mathrm{L}^{-1}\right)$ is the concentration at equilibrium, $q_{e}$ is the amount adsorbed, and $q_{m}$ is the maximum amount of adsorbent to form a complete monolayer on the surface. $K_{\mathrm{L}}\left(\mathrm{mg}^{-1}\right)$ is the Langmuir constant which indicates the extent of interaction between the adsorbate and surface.

The Freundlich model describes the nonideal and reversible adsorption processes that occur on heterogeneous surfaces and active sites of different energies based on multilayer adsorption and equilibrium [51]. The linear form of the Freundlich isotherm model is represented as follows:

$$
\log q_{e}=\log K_{\mathrm{F}}+\frac{1}{n} \log C_{e},
$$

where $K_{\mathrm{F}}$ is the Freundlich isotherm constant and $n$ is the adsorption intensity.

The D-R isotherm model assumes that the mechanism is related to the porosity of the adsorbent rather than surface
TABLE 3: Adsorption isotherm parameters for the adsorption of MB onto BC500.

\begin{tabular}{lcc}
\hline Model & Parameter & Value \\
\hline \multirow{4}{*}{ Langmuir } & $q_{m}\left(\mathrm{mg} \mathrm{g}^{-1}\right)$ & 86.63 \\
& $K_{L}\left(\mathrm{mg}^{-1}\right)$ & 0.05 \\
& $R_{L}$ & 0.048 \\
Freundlich & $R^{2}$ & 0.9795 \\
& $K_{F}\left(\mathrm{mgg}^{-1}\left(\mathrm{~L} \mathrm{mg}^{-1}\right)^{1 / \mathrm{n}}\right)$ & 3.35 \\
Temkin & $n$ & 3.44 \\
& $R^{2}$ & 0.6117 \\
& $A_{T}$ & 0.61 \\
D-R & $b_{T}$ & 0.53 \\
& $R^{2}$ & 0.6066 \\
& $q_{m}\left(\mathrm{mg} \mathrm{g}^{-1}\right)$ & -76.68 \\
& $K_{d r}\left(\mathrm{~mol}^{2} \mathrm{~kJ}^{-2}\right)$ & 0.0130 \\
& $\varepsilon\left(\mathrm{kJ} \mathrm{mol}^{-1}\right)$ & 6.19 \\
& $q_{s}\left(\mathrm{~mol} \mathrm{~g}^{-1}\right)$ & 1.07 \\
$R^{2}$ & 0.7841 \\
\hline
\end{tabular}

coverage with a monolayer or multilayer. One of its distinguishing features is that it is temperature-dependent and is mainly used to predict whether the adsorption process is physical or chemical [52]. The linearised equation is as follows:

$$
\ln \left(q_{e}\right)=\ln \left(q_{s}\right)-K_{d r} \varepsilon^{2}
$$

where $q_{e}\left(\mathrm{mg} \mathrm{g}^{-1}\right)$ represents the amount of adsorbate adsorbed at equilibrium. $K_{d r}\left(\mathrm{~mol}^{2} \mathrm{~kJ}^{-2}\right)$ is the mean free energy of adsorption, and $\varepsilon$ refers to the Polanyi potential.

The Temkin model considers the heat of adsorption as a function of temperature. All molecules in the layer would decrease in a linear manner instead of logarithmically with 


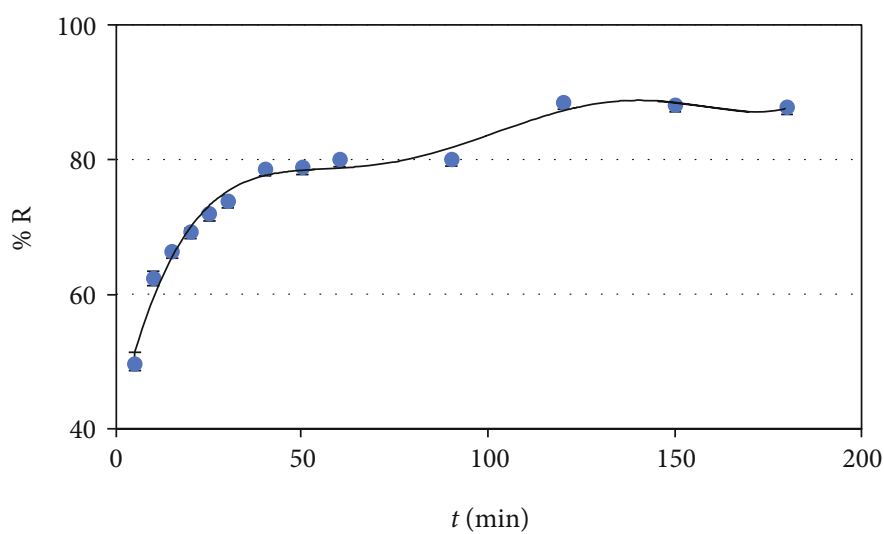

Figure 5: The effect of contact time on the adsorption of MB using BC500 (room temperature, unadjusted $\mathrm{pH}$, and $C_{i}=100 \mathrm{ppm}$ ).

coverage at average concentrations [53]. The model is expressed as

$$
q_{e}=\frac{R T}{b_{\mathrm{T}}} \ln A_{\mathrm{T}}+\left(\frac{R T}{b_{\mathrm{T}}}\right) \ln C_{e}
$$

where $A_{\mathrm{T}}$ is the Temkin isotherm equilibrium binding constant $\left(\mathrm{Lg}^{-1}\right), b_{\mathrm{T}}$ is the Temkin isotherm constant, $R$ is the universal gas constant $\left(8.314 \mathrm{~J} \mathrm{~mol}^{-1} \mathrm{~K}^{-1}\right)$, and $T$ is the temperature at $298 \mathrm{~K}$.

\section{Results and Discussions}

3.1. The Yield of Biochar. As seen from Table 1, the yield of biochar at pyrolysis temperature of $400^{\circ} \mathrm{C}$ is at $4.85 \%$. As the pyrolysis temperature increases to $500^{\circ} \mathrm{C}$, the biochar yield increases to $11.4 \%$. Any further increase in temperature beyond $500^{\circ} \mathrm{C}$ resulted in a decrease in the biochar yield. This nonlinear behaviour is also reported by Açıkalın et al. in which biochar was produced using pistachio shell at pyrolysis temperature between 350 and $650^{\circ} \mathrm{C}$, and the highest biochar yield was obtained at $500^{\circ} \mathrm{C}$ [54].

3.2. Effect of Pyrolysis Temperature in Dye Adsorption. The effect of pyrolysis temperature on the adsorption of $\mathrm{MB}$ using biochar can be seen in Figure 1. The pyrolysis temperature of $500^{\circ} \mathrm{C}$ resulted in the highest removal of $\mathrm{MB}$ dye from aqueous solution at $81.8 \%\left(q_{e}=28.1 \mathrm{mg} \mathrm{g}^{-1}\right)$, while the temperature of $800^{\circ} \mathrm{C}$ resulted in the lowest removal $11.1 \%\left(q_{e}=5.7 \mathrm{mg} \mathrm{g}^{-1}\right)$. This behaviour may be related to the average pore diameter $\left(D_{\mathrm{p}}\right)$ of BC. Naturally, a larger $D_{\mathrm{p}}$ will allow more dye molecules to move inside the pores with less chance of getting clogged when compared to a smaller $D_{\mathrm{p}}$. As seen in Table 2, BC500 has the largest $D_{\mathrm{p}}$ at $14.6 \mathrm{~nm}$, while BC400, BC600, BC700, and BC800 were much smaller at $5.00,7.74,8.54$, and $8.65 \mathrm{~nm}$, respectively. Since BC500 showed the utmost performance, therefore, complete adsorption experiment was only carried out for BC500.

3.3. BET. The pyrolysis of biomass resulted in the decomposition of lignin and the quick release of $\mathrm{H}_{2}$ and $\mathrm{CH}_{4}$. These gases magnified the surface area and pore volume, particu-
TABLE 4: Kinetic model parameters for the adsorption of MB onto BC500.

\begin{tabular}{lcc}
\hline Model & Parameter & Value \\
\hline Pseudo-first order & $k_{1}\left(\mathrm{~min}^{-1}\right)$ & 0.0290 \\
& $R^{2}$ & 0.9621 \\
Pseudo-second order & $k_{2}\left(\mathrm{mg} \mathrm{g}^{-1} \mathrm{~min}^{-1}\right)$ & 0.0037 \\
Weber-Morris & $R^{2}$ & 0.9986 \\
& $k_{3}\left(\mathrm{mg} \mathrm{g}^{-1} \mathrm{~min}^{-0.5}\right)$ & 1.4931 \\
\hline
\end{tabular}

larly for the micropores. This is mostly attributed to the further degradation of lignin and the reaction of aromatic condensation, which in turn increases the release of volatile matter, creating more pores $[42,55,56]$. These pores can be characterised using the Brunauer-Emmett-Teller (BET) surface area analysis to obtain useful insights such as the adsorbent's surface area $\left(S_{\mathrm{BET}}\right)$, total pore volume $\left(V_{\mathrm{TOTAL}}\right)$, and $D_{\mathrm{p}}$.

The results of the BET surface area analysis are summarised in Table 2. BC400 has the highest $S_{\mathrm{BET}}$ and $V_{\text {TOTAL }}$ at $28.4 \mathrm{~m}^{2} \mathrm{~g}^{-1}$ and $0.032 \mathrm{~cm}^{3} \mathrm{~g}^{-1}$, respectively, while BC500 has the lowest $S_{\mathrm{BET}}$ at $4.15 \mathrm{~m}^{2} \mathrm{~g}^{-1}$ and $0.015 \mathrm{~cm}^{3} \mathrm{~g}^{-1}$. However, the BC500 has the highest $D_{\mathrm{p}}$ at $14.6 \mathrm{~nm}$, while the lowest was for BC400 at $5.0 \mathrm{~nm}$.

The $S_{\mathrm{BET}}, V_{\mathrm{TOTAL}}$, and $D_{\mathrm{p}}$ are observed not to be in a linear relationship with the increasing temperature. This is partially due to varying proportions of micropore $\left(D_{\mathrm{p}}<2 \mathrm{~nm}\right)$ and mesopore $\left(D_{\mathrm{p}} 2-50 \mathrm{~nm}\right)$ that form at a different range of temperature, which is observed by Fu et al. in their study of rice straw biochar [57].

3.4. Effect of Adsorbent Dosage. The effect of the adsorbent dosage on the $\mathrm{MB}$ removal was investigated using various masses of BC500 (0.01 g to $0.06 \mathrm{~g})$ at a fixed volume $(20 \mathrm{~mL})$ of the adsorbate. It can be observed in Figure 2 that the removal of dye increased as the mass of adsorbents increased from $0.01 \mathrm{~g}$ to $0.03 \mathrm{~g}$. This is due to more adsorption sites being available at higher adsorbent dosages. However, beyond the adsorbent dosage of $0.03 \mathrm{~g}$, there is no 


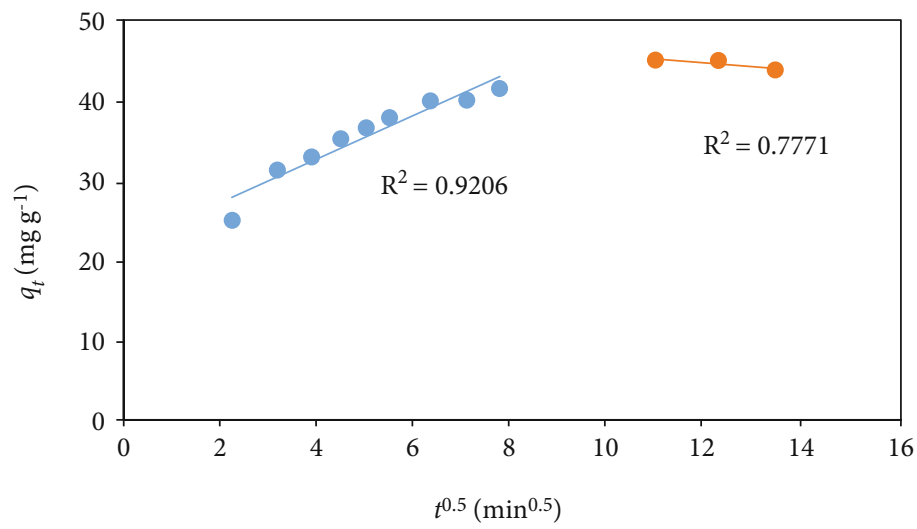

Figure 6: Weber-Morris plot.

further increase in the removal of $\mathrm{MB}$, which may be due to the overcrowding of adsorbent particles in such a way that overlapped the adsorption sites [58]. As the adsorbent dosage that performed the best was $0.03 \mathrm{~g}$ with a percentage removal of $77.6 \%\left(q_{e}=51.0 \mathrm{mgg}^{-1}\right)$, therefore, the rest of the adsorption experiment was carried out at this adsorbent dosage.

3.5. Effect of $\mathrm{pH}$. As seen from Figure 3, the change in $\mathrm{pH}$ has no large impact on the $\mathrm{pH}$. The removal of $\mathrm{MB}$ $\left(C_{i}=100 \mathrm{ppm}\right.$, unadjusted $\mathrm{pH}$ at 7.0$)$ was at $74.3 \%$ $\left(q_{e}=39.2 \mathrm{mg} \mathrm{g}^{-1}\right)$. As $\mathrm{pH}$ increased to 10 , the removal of $\mathrm{MB}$ was at $74.1 \%\left(q_{e}=40.3 \mathrm{mgg}^{-1}\right)$, while for acidic $\mathrm{pH}$ (2.4), the removal was at $80.6 \%\left(q_{e}=41.0 \mathrm{mgg}^{-1}\right)$. This behaviour is commonly observed with the adsorption of $\mathrm{MB}$ dye, which was also reported in removing MB using biomass adsorbent derived from Azolla pinnata [59].

3.6. Effect of Initial Concentration and Isotherm Modelling. The effect of the initial MB concentration is shown in Figure 4 . There was a gradual increase in $q_{e}$ as the $C_{i}$ increased from $20 \mathrm{ppm}$ to $200 \mathrm{ppm}$. The reason for this observation is the availability of adsorption sites on the adsorbent's surface. Beyond $200 \mathrm{ppm}$, no further increase in $q_{e}$ is due to the saturation of the adsorption sites and no further possible uptake of $\mathrm{MB}$ molecules at this adsorption condition.

To understand more about the adsorption system, the adsorption data were fitted into various adsorption isotherm models. The parameters of the isotherm models are summarised in Table 3, where it can be observed that the correlation coefficient of determination $\left(R^{2}\right)$ is highest for the Langmuir at 0.9795, followed by Dubinin-Radushkevich $\left(R^{2}=0.7841\right)$, Freundlich $\left(R^{2}=0.6117\right)$, and Temkin $\left(R^{2}=0.6066\right)$ models. The highest value of $R^{2}$ makes the Langmuir model most suitable to describe the adsorption process and indicate the possibility of forming a single layer of $\mathrm{MB}$ on the surface of BC500. The $R_{\mathrm{L}}$ value assumes the nature and the feasibility of the adsorption process, and since the value was determined to be 0.048 , the adsorption process is considered favourable.

The $q_{m}$, calculated from the Langmuir isotherm model, is one of the most commonly used metrics for comparing the performance of various adsorbents in the removal of a particular adsorbate. The $q_{m}$ of the BC500 was calculated to be at $86.3 \mathrm{mg} \mathrm{g}^{-1}$ and is compared to adsorbents reported in the literature such as Azolla pinnata $\left(80.6 \mathrm{mgg}^{-1}\right)$ [59], Lathyrus sativus husk (98.3 $\left.\mathrm{mgg}^{-1}\right)$ [60], Casuarina leaf $\left(110.8 \mathrm{mg} \mathrm{g}^{-1}\right)$ [9], eucalyptus leaves (194.3 $\left.\mathrm{mgg}^{-1}\right)$ [61], jackfruit leaf $\left(271 \mathrm{mg} \mathrm{g}^{-1}\right)$ [62], and zinc chloride activated carbon $\left(462.9 \mathrm{mgg}^{-1}\right)$ [63].

3.7. Effect of Contact Time and Kinetic Modelling. The effect of contact time on removing $\mathrm{MB}\left(C_{i}=100 \mathrm{ppm}\right.$, unadjusted $\mathrm{pH}$, and room temperature) is shown in Figure 5, where there was a rapid increase in adsorption of $\mathrm{MB}$ from time 0 to $40 \mathrm{~min}$. The rapid rate of adsorption was mainly due to the availability of sites for dye adsorption [44]. Beyond the contact time of $40 \mathrm{~min}$, the adsorption rate slows down as adsorption sites are gradually taken up until there is no further increase in adsorption beyond $120 \mathrm{~min}$. Thus, the contact time of $120 \mathrm{~min}$ is deemed sufficient for this adsorption system to achieve equilibrium.

The adsorption data were fitted with various kinetic models to study the kinetics of the adsorption processes, and the kinetic parameters are summarised in Table 4. By comparing the $R^{2}$ values between the models, the pseudosecond order best described the experimental kinetic data $\left(R^{2}=0.9986\right)$, implying that the chemisorption may dominate the adsorption process.

To gain insight into the diffusion process, kinetic data were fitted into the Weber-Morris model and the plot is shown in Figure 6. The Weber-Morris plot did not cross the origin $(Y$-intercept $\neq 0)$, which indicates that the intraparticle diffusion is not the rate-limiting step, and the "bottleneck" of the adsorption may be due to other processes.

\subsection{Characterisations of the Adsorbents}

3.8.1. SEM and EDX. The SEM images are shown in Figure 7. The surface morphology of the BC500 is rough and distorted in appearance with some irregular microstructures. However, after adsorption with $\mathrm{MB}$, the surface is smoother with less visible microstructures, and this may indicate the deposition of MB onto the adsorbent's surface. 


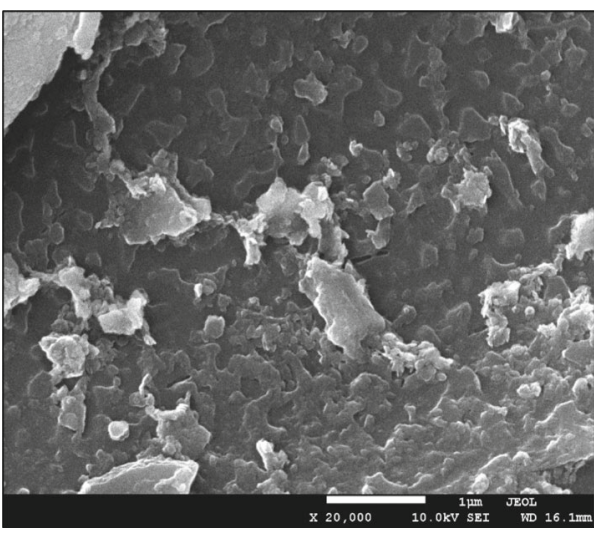

(a)

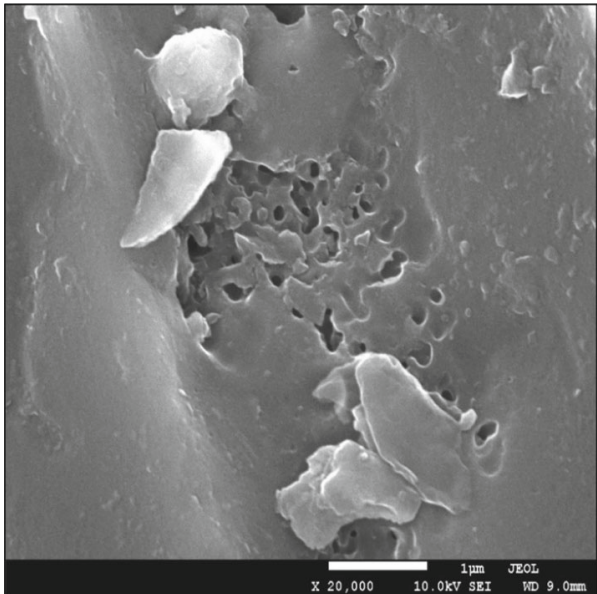

(b)

Figure 7: SEM images of BC500 (a) before and (b) after MB adsorption.

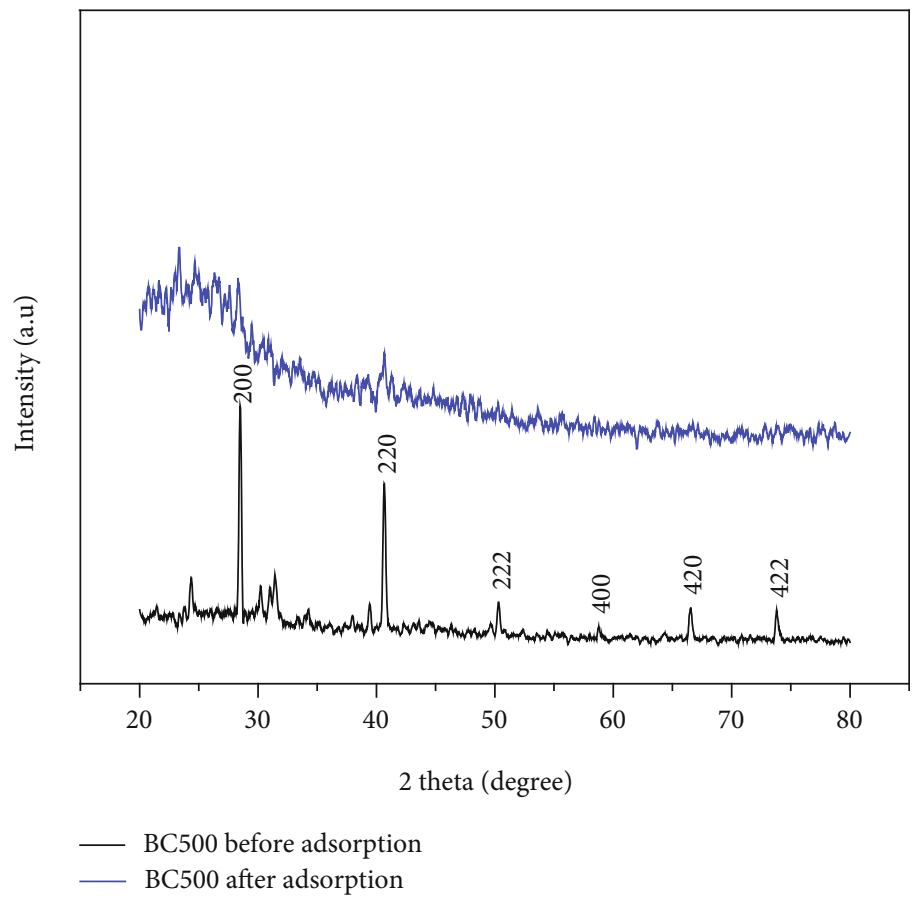

FIGURE 8: The XRD spectra of BC500 before and after MB adsorption.

The elements present on BC500 were identified using EDX. The EDX revealed the presence of $\mathrm{C}, \mathrm{O}, \mathrm{S}, \mathrm{Cl}$, and $\mathrm{K}$ with the normalised weight percentage at $82.9,11.3,0.33$, 0.29 , and $4.65 \%$, respectively. However, after the MB adsorption, only the elements $\mathrm{C}, \mathrm{O}, \mathrm{S}$, and $\mathrm{K}$ were detected at 88.0 , $9.42,0.23$, and $2.36 \%$, respectively. Also, notice that $\mathrm{K}$ and $\mathrm{Cl}$ percentages have reduced after adsorption; this could be due to the mobility and solubility of the $\mathrm{K}$ and $\mathrm{Cl}$ ions easily washed into the aqueous phase during the adsorption process. A similar finding is also reported in the adsorption of methyl violet $2 \mathrm{~B}$ dye using biomass Azolla pinnata as the adsorbent [64].
3.8.2. $X R D$. XRD is a valuable analytical technique for the identification of crystallinity in a material. The XRD spectra of the BC500 before and after the adsorption of $\mathrm{MB}$ are shown in Figure 8. For BC500 before the adsorption, diffraction peaks at $28.4,40.6,50.2,58.7,66.4$, and $73.7^{\circ}$ are assigned (200), (220), (222), (400), (420), and (422) crystal planes of sylvite $(\mathrm{KCl})$, respectively, and are consistent with findings by Yuan et al. and $\mathrm{He}$ et al. [65, 66]. Those intense sharp peaks suggest that $\mathrm{KCl}$ content is high in BC500 before the adsorption. There was no intense peak observed in the XRD spectra for BC500 after the MB adsorption; however, there is a broad diffraction peak at $2 \theta$ value 


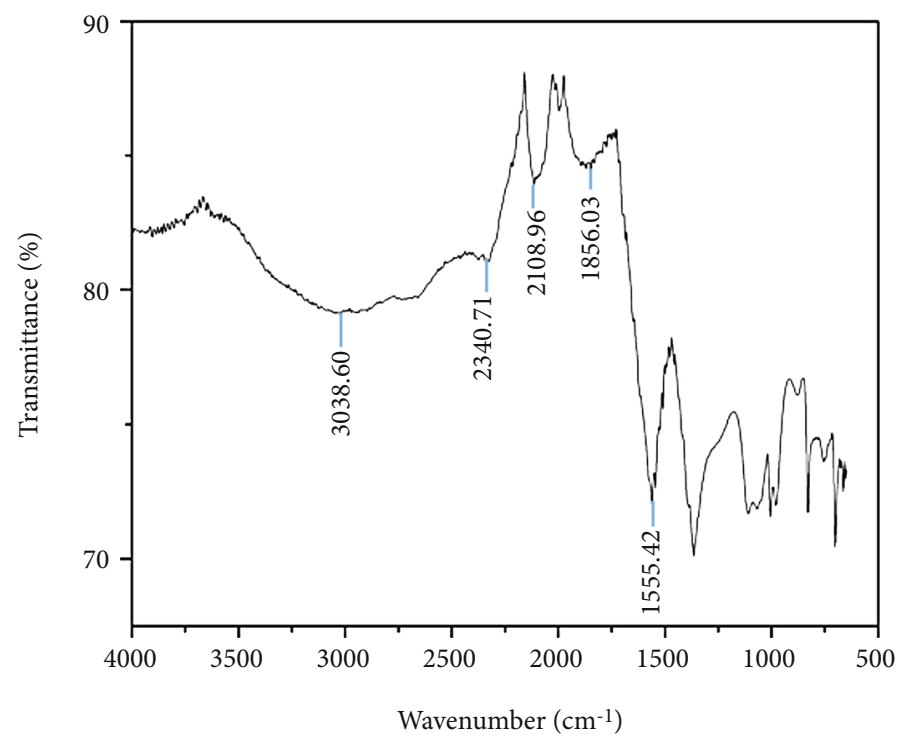

(a)

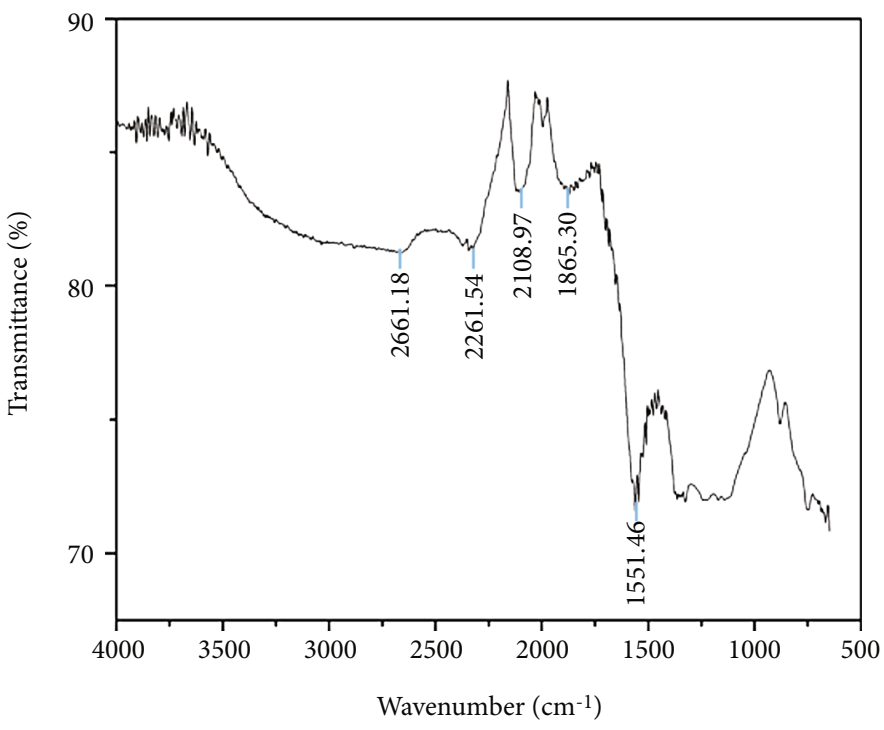

(b)

FIgURE 9: FTIR analysis for BC500 (a) before and (b) after the MB adsorption.

$22^{\circ}$, which is due to the amorphous carbon of the adsorbent after adsorption. This might be that $\mathrm{KCl}$ is dissolved and washed away into the solution during the adsorption process, as discussed in the previous section.

3.8.3. FTIR. The purpose of FTIR analysis is to identify the functional groups that interact with the MB molecules. The molecular structure was similar to the biochar produced; hence, for brevity, only the FTIR plot for BC500 before and after treatment is shown in Figure 9.

The FTIR spectrum of BC500 without MB treatment showed a broad peak at $3038 \mathrm{~cm}^{-1}$, which is assigned to the $\mathrm{O}-\mathrm{H}$ stretching, indicating that some moisture was absorbed from the air. The stretching at $2340 \mathrm{~cm}^{-1}$ is attributed to the $\mathrm{O}-\mathrm{H}$ bond stretch of a carboxylic acid group [67]. The peak at $1856 \mathrm{~cm}^{-1}$ was related to the stretching vibration of $\mathrm{C}=\mathrm{O}$ of the carbonyl group. In contrast, the $1555 \mathrm{~cm}^{-1}$ was associated with the stretching vibration of $\mathrm{C}=\mathrm{C}$ and may be due to the benzene ring skeleton in lignin mainly from aromatic [54]. For the MB-treated BC500, there is a shift of peaks such as $2261 \mathrm{~cm}^{-1}(\mathrm{O}-\mathrm{H}$ stretch of the carboxylic group), $1865 \mathrm{~cm}^{-1}$ ( $\mathrm{C}=\mathrm{O}$ stretch of the carbonyl group), and $1551 \mathrm{~cm}^{-1}$ (aromatic), indicating that these functional groups may have interacted with the MB dyes.

The BET analysis was carried out for BC500 before and after the MB adsorption. The results revealed that after MB adsorption, the BET surface area decreased from 4.1519 to $3.2413 \mathrm{~m}^{2} \mathrm{~g}^{-1}$, while the total pore volume was from 0.015165 to $0.008817 \mathrm{~cm}^{3} \mathrm{~g}^{-1}$, and lastly, the pore diameter was from 14.61015 to $9.7603 \mathrm{~nm}$, respectively. The molecular dimension of $\mathrm{MB}$ is approximately $0.7 \times 1.7 \mathrm{~nm}$ [68], which indicates that the pore diameter and pore volume of 
BC500 are relatively higher than those of the MB molecules. Therefore, the MB molecules easily enter the pores of BC500, filling them and leading to the decreasing surface area, pore volume, and pore diameter of BC500 after the adsorption process.

3.9. Adsorption Mechanism. The mechanism of dye adsorption is well established, and the three dominant forces involved in dye interaction are electrostatic interaction, hydrogen bonding, and hydrophobic-to-hydrophobic interaction $[69,70]$. Several active functional groups such as $\mathrm{O}-\mathrm{H}$ stretch of the carboxylic group and $\mathrm{C}=\mathrm{O}$ stretch of the carbonyl group (as described in the previous section) are capable of interacting with $\mathrm{MB}$ by hydrogen bonding or electrostatic attraction, while the aromatic groups on the adsorbent's surface may interact by hydrophobic-tohydrophobic interaction. Similar findings were reported in removing MB using Casuarina leaf [9] and removing malachite green dye using Azolla pinnata [71].

\section{Conclusion}

In summary, this study investigated the effect of pyrolysis temperature on a species of Gigantochloa bamboo to derive biochar for the removal of MB from the aqueous solution. It was revealed that pyrolysis temperature of $500^{\circ} \mathrm{C}$ resulted in the highest biochar yield at $11.39 \%$ and also possessed the highest adsorptive performance when compared to biochar produced at other temperatures. The SEM image revealed the rough surface of biochar which becomes smoother after $\mathrm{MB}$ adsorption, while EDX data reveal the composition of $\mathrm{C}$, $\mathrm{O}, \mathrm{S}, \mathrm{Cl}$, and $\mathrm{K}$ elements in BC500. The XRD data reconfirms the presence of $\mathrm{KCl}$ by having crystal peaks at 28.4, 40.6, 50.2, 58.7, 66.4, and $73.7^{\circ}$, while FTIR confirms the BC500 interaction with $\mathrm{MB}$ by having carboxylic, carbonyl, and aromatic functional groups. $S_{\mathrm{BET}}$ data revealed a decrease in the BET surface area and pore volume after adsorption, further confirming the adsorption of MB. The optimised adsorbent dosage for removal of $\mathrm{MB}$ is at $0.03 \mathrm{~g}$ and aqueous $\mathrm{pH}$ of 2 , and the equilibrium was achieved within $120 \mathrm{~min}$ of contact time. The kinetic data is best represented by the pseudo-secondorder model, indicating that the chemisorption dominates during the adsorption process. On the other hand, the Langmuir model best describes the adsorption process hinting at the formation of a monolayer of the adsorbate on the adsorbent's surface. Based on the results, it can be concluded that the pyrolysis temperature significantly impacts the physicochemical characteristics of the biochar and thus influences the adsorptive performance of MB.

\section{Data Availability}

All the data used to support the findings of this study are included within the article.

\section{Additional Points}

Research Highlight. Biochar was produced using the Gigantochloa bamboo as feedstock for pyrolysis. Several pyrolysis temperatures $\left(400\right.$ to $\left.800^{\circ} \mathrm{C}\right)$ were investigated. The adsorption conditions for removal of methylene blue $(\mathrm{MB})$ were optimised. Pyrolysis temperature of $500^{\circ} \mathrm{C}$ produced biochar with the highest adsorptive performance in removal of $\mathrm{MB}$ from aqueous solution.

\section{Conflicts of Interest}

All authors declare no conflict of interest.

\section{Acknowledgments}

We, the authors, would like to thank the Government of Brunei Darussalam and Universiti Brunei Darussalam for their continuous support. The work described in this paper was supported by Universiti Brunei Darussalam research grants UBD/RSCH/1.9/FICBF/2021/010 and UBD/RSCH/ 1.9/FICBF/2021/008 and Ministry of Science and Technology of Taiwan (MOST 109-2112-M-019-001).

\section{References}

[1] S. C. Bhatia and S. Devraj, Pollution Control in Textile IndustryNew York, WPI Publishing.

[2] K. Ali, M. U. Javaid, Z. Ali, and M. J. Zaghum, "BiomassDerived Adsorbents for Dye and Heavy Metal Removal from Wastewater," Adsorption Science \& Technology, vol. 2021, article 9357509, pp. 1-14, 2021.

[3] S. Khan and A. Malik, "Toxicity evaluation of textile effluents and role of native soil bacterium in biodegradation of a textile dye," Environmental Science and Pollution Research International, vol. 25, pp. 4446-4458, 2018.

[4] N. M. Zain, C. M. Lim, A. Usman, N. Keasberry, R. Thotagamuge, and A. H. Mahadi, "Synergistic effect of $\mathrm{TiO}_{2}$ size on activated carbon composites for ruthenium N-3 dye adsorption and photocatalytic degradation in wastewater treatment," Environmental Nanotechnology, Monitoring and Management, vol. 16, article 100567, 2021.

[5] A. Masanizan, C. M. Lim, M. R. R. Kooh, A. H. Mahadi, and R. Thotagamuge, "The Removal of Ruthenium-Based Complexes N3 Dye from DSSC Wastewater Using Copper Impregnated KOH-Activated Bamboo Charcoal," Water, Air, \& Soil Pollution, vol. 232, no. 9, 2021.

[6] M. P. Elizalde-González and A. A. Peláez-cid, "Removal of textile dyes from aqueous solutions by adsorption on biodegradable wastes," Environmental Technology, vol. 24, pp. 821829, 2003.

[7] V. Yadav, J. Ali, and M. C. Garg, "Biosorption of methylene blue dye from textile-industry wastewater onto sugarcane bagasse: response surface modeling, isotherms, kinetic and thermodynamic modeling," Journal of Hazardous, Toxic, and Radioactive Waste, vol. 25, no. 1, article 04020067, 2021.

[8] E. H. Abd Latib, M. Suraya Mustfha, S. Sufian, and K. Z. Ku Shaari, "Methylene Blue Dye Adsorption to Durian Shell Activated Carbon," Key Engineering Materials, vol. 594-595, pp. 350-355, 2013.

[9] M. K. Dahri, M. R. R. Kooh, and L. B. L. Lim, "Application of Casuarina equisetifolia needle for the removal of methylene blue and malachite green dyes from aqueous solution," Alexandria Engineering Journal, vol. 54, pp. 1253-1263, 2015. 
[10] M. A. Barakat, "New trends in removing heavy metals from industrial wastewater," Arabian Journal of Chemistry, vol. 4, pp. 361-377, 2011.

[11] Y. G. Zeng and L. Li, "Study on treatment of heavy metal lons of chemical wastewater by ion exchange resin," Advanced Materials Research, vol. 955-959, pp. 2230-2233, 2014.

[12] P. M. Godwin, Y. Pan, H. Xiao, and M. T. Afzal, "Progress in Preparation and Application of Modified Biochar for Improving Heavy Metal Ion Removal From Wastewater," Journal of Bioresources and Bioproducts, vol. 4, pp. 31-42, 2019.

[13] A. Pohl, "Removal of heavy metal ions from water and wastewaters by sulfur-containing precipitation agents," Water, Air, \& Soil Pollution, vol. 231, no. 10, 2020.

[14] M. Wołowiec, M. Komorowska-kaufman, A. Pruss, G. Rzepa, and T. Bajda, "Removal of heavy metals and metalloids from water using drinking water treatment residuals as adsorbents: A review," Minerals, vol. 9, no. 8, p. 487, 2019.

[15] M. R. R. Kooh, L. B. L. Lim, L. H. Lim, and O. A. Malik, "Phytoextraction potential of water fern (Azolla pinnata) in the removal of a hazardous dye, methyl violet 2B: Artificial neural network modelling," International Journal of Phytoremediation, vol. 20, pp. 424-431, 2018.

[16] J. Ouyang, L. Zhou, Z. Liu, J. Y. Y. Heng, and W. Chen, "Biomass-derived activated carbons for the removal of pharmaceutical mircopollutants from wastewater: A review," Separation and Purification Technology, vol. 253, article 117536, 2020.

[17] J. Liu, S. Ren, J. Cao et al., "Highly efficient removal of thallium in wastewater by $\mathrm{MnFe}_{2} \mathrm{O}_{4}$-biochar composite," Journal of Hazardous Materials, vol. 401, article 123311, 2021.

[18] W. Yu, J. Hu, Y. Yu et al., "Facile preparation of sulfonated biochar for highly efficient removal of toxic $\mathrm{Pb}(\mathrm{II})$ and $\mathrm{Cd}(\mathrm{II})$ from wastewater," Science of the Total Environment, vol. 750, article 141545, 2021.

[19] Y. C. Lu, M. R. R. Kooh, L. B. L. Lim, and N. Priyantha, "Effective and Simple $\mathrm{NaOH}$-Modification Method to Remove Methyl Violet Dye via Ipomoea aquatica Roots," Adsorption Science and Technology, vol. 2021, article 5932222, 12 pages, 2021.

[20] V. K. Gupta and Suhas, "Application of low-cost adsorbents for dye removal - A review," Journal of Environmental Management, vol. 90, pp. 2313-2342, 2009.

[21] D. H. A. Sudarni, U. O. Aigbe, K. E. Ukhurebor et al., "Malachite green removal by activated potassium hydroxide clove leaf agrowaste biosorbent: Characterization, Kinetic, Isotherm, and Thermodynamic Studies," Adsorption Science \& Technology, vol. 2021, article 1145312, 15 pages, 2021.

[22] Y. Hou, G. Huang, J. Li, Q. Yang, S. Huang, and J. Cai, "Hydrothermal conversion of bamboo shoot shell to biochar: Preliminary studies of adsorption equilibrium and kinetics for rhodamine B removal," Journal of Analytical and Applied Pyrolysis, vol. 143, article 104694, 2019.

[23] D. Pratiwi, D. J. Prasetyo, and C. D. Poeloengasih, "Adsorption of Methylene Blue dye using Marine algae Ulva lactuca," IOP Conference Series: Earth and Environmental Science, vol. 251, no. 1, p. 012012, 2019.

[24] A. A. Romzi, M. R. R. Kooh, L. B. L. Lim, N. Priyantha, and C. M. Chan, "Environmentally friendly adsorbent derived from rock melon skin for effective removal of toxic brilliant green dye: linear versus non-linear analyses," International Journal of Environmental Analytical Chemistry, 2021.

[25] P. T. Le, H. T. Bui, D. N. Le et al., "Preparation and Characterization of Biochar Derived from Agricultural By- Products for
Dye Removal," Adsorption Science \& Technology, vol. 2021, article 9161904, pp. 1-14, 2021.

[26] M. B. Amar, K. Walha, and V. Salvadó, "Valorisation of Pine Cone as an Efficient Biosorbent for the Removal of $\mathrm{Pb}(\mathrm{II})$, $\mathrm{Cd}(\mathrm{II}), \mathrm{Cu}(\mathrm{II})$, and Cr(VI)," Adsorption Science \& Technology, vol. 2021, article 6678530, pp. 1-12, 2021.

[27] R. Thotagamuge, M. R. R. Kooh, A. H. Mahadi et al., "Copper modified activated bamboo charcoal to enhance adsorption of heavy metals from industrial wastewater," Environmental Nanotechnology, Monitoring and Management, vol. 16, article 100562, 2021.

[28] S. Babel and T. A. Kurniawan, "Low-cost adsorbents for heavy metals uptake from contaminated water: A review," Journal of Hazardous Materials, vol. 97, pp. 219-243, 2003.

[29] X. Chen, G. Zhang, J. Li, and P. Ji, "Possibility of removing Pb and Cd from polluted water by modified fly ash," Adsorption Science \& Technology, vol. 2021, article 1336638, pp. 1-8, 2021.

[30] X. Wang, X. Tan, Y. Liu et al., "Application of biochar for the removal of pollutants from aqueous solutions," Chemosphere, vol. 125, pp. 70-85, 2015.

[31] S. S. M. Isa, M. M. Ramli, N. A. M. A. Hambali et al., "Adsorption properties and potential applications of bamboo charcoal: A review," MATEC Web of Conferences, vol. 78, p. 01097, 2016.

[32] M. Li, Q. Liu, L. Guo et al., " $\mathrm{Cu}$ (II) removal from aqueous solution by Spartina alterniflora derived biochar," Bioresource Technology, vol. 141, pp. 83-88, 2013.

[33] J. Jin, M. Wang, Y. Cao et al., "Cumulative effects of bamboo sawdust addition on pyrolysis of sewage sludge: Biochar properties and environmental risk from metals," Bioresource Technology, vol. 228, pp. 218-226, 2017.

[34] N. N. B. Rosli, L. C. Ming, A. H. Mahadi, S. Wattanasiriwech, R. C. Lim, and N. T. R. N. Kumara, "Ruthenium dye (N3) removal from simulated wastewater using bamboo charcoal and activated bamboo charcoal," Key Engineering Materials, vol. 765, pp. 92-98, 2018.

[35] M. Uchimiya, L. H. Wartelle, K. T. Klasson, C. A. Fortier, and I. M. Lima, "Influence of pyrolysis temperature on biochar property and function as a heavy metal sorbent in soil," Journal of Agricultural and Food Chemistry, vol. 59, pp. 25012510, 2011.

[36] D. Chen, X. Yu, C. Song, X. Pang, J. Huang, and Y. Li, “Effect of pyrolysis temperature on the chemical oxidation stability of bamboo biochar," Bioresource Technology, vol. 218, pp. 1303-1306, 2016.

[37] B. Sizirici, Y. H. Fseha, I. Yildiz, T. Delclos, and A. Khaleel, "The effect of pyrolysis temperature and feedstock on date palm waste derived biochar to remove single and multimetals in aqueous solutions," Sustainable Environment Research, vol. 31, no. 1, p. 9, 2021.

[38] H. Huang, N. G. Reddy, X. Huang et al., "Effects of pyrolysis temperature, feedstock type and compaction on water retention of biochar amended soil," Scientific Reports, vol. 11, article 7419, 2021.

[39] J. Sun, F. Lian, Z. Liu, L. Zhu, and Z. Song, "Biochars derived from various crop straws: Characterization and Cd(II) removal potential," Ecotoxicology and Environmental Safety, vol. 106, pp. 226-231, 2014.

[40] B. Li, L. Yang, C. Q. Wang et al., "Adsorption of Cd(II) from aqueous solutions by rape straw biochar derived from different modification processes," Chemosphere, vol. 175, pp. 332-340, 2017. 
[41] L. Gao, Z. Li, W. Yi et al., "Impacts of pyrolysis temperature on lead adsorption by cotton stalk-derived biochar and related mechanisms," Journal of Environmental Chemical Engineering, vol. 9, no. 4, article 105602, 2021.

[42] R. Chatterjee, B. Sajjadi, W. Y. Chen et al., "Effect of Pyrolysis Temperature on PhysicoChemical Properties and AcousticBased Amination of Biochar for Efficient CO2 Adsorption," Frontiers in Energy Research, vol. 8, pp. 1-18, 2020.

[43] S. Iftekhar, D. L. Ramasamy, V. Srivastava, M. B. Asif, and M. Sillanpää, "Understanding the factors affecting the adsorption of Lanthanum using different adsorbents: A critical review," Chemosphere, vol. 204, pp. 413-430, 2018.

[44] N. Tiadi, M. Mohanty, C. R. Mohanty, and H. P. Panda, "Studies on adsorption behavior of an industrial waste for removal of chromium from aqueous solution," South African Journal of Chemical Engineering, vol. 23, pp. 132-138, 2017.

[45] M. A. Mohammad Razi, M. N. A. Mohd Hishammudin, and R. Hamdan, "Factor affecting textile dye removal using adsorbent from activated carbon: A review," MATEC Web of Conferences, vol. 103, p. 06015, 2017.

[46] D. M. G. Saad, E. M. Cukrowska, and H. Tutu, "Phosphonated cross-linked polyethylenimine for selective removal of uranium ions from aqueous solutions," Water Science and Technology, vol. 66, pp. 122-129, 2012.

[47] D. Pathania, S. Sharma, and P. Singh, "Removal of methylene blue by adsorption onto activated carbon developed from Ficus carica bast," Arabian Journal of Chemistry, vol. 10, pp. S1445-S1451, 2017.

[48] S. Lagergren, "Zur theorie der sogenannten adsorption geloster stoffe," Kungliga Svenska Vetenskapsakademiens Handlingar, vol. 24, pp. 1-39, 1898.

[49] Y.-S. Ho and G. McKay, "Pseudo-second order model for sorption processes," Process Biochemistry, vol. 34, pp. 451465, 1999.

[50] I. Langmuir, "The constitution and fundamental properties of solids and liquids. II. Liquids," Journal of the American Chemical Society, vol. 39, pp. 1848-1906, 1917.

[51] H. M. F. Freundlich, "Over the adsorption in solution," The Journal of Physical Chemistry, vol. 57, pp. 1100-1107, 1906.

[52] M. M. Dubinin and L. V. Radushkevich, "Equation of the Characteristic Curve of Activated Carbon," Proceedings of the National Academy of Sciences of the United States of America, vol. 55, pp. 327-329, 1947.

[53] M. I. Temkin, "Kinetics of ammonia synthesis on promoted iron catalysts," Acta Physiochimica URSS, vol. 12, pp. 327356, 1940.

[54] K. Açıkalın, F. Karaca, and E. Bolat, "Pyrolysis of pistachio shell: effects of pyrolysis conditions and analysis of products," Fuel, vol. 95, pp. 169-177, 2012.

[55] Y. Zhang, Z. Ma, Q. Zhang et al., "Comparison of the physicochemical characteristics of bio-char pyrolyzed from moso bamboo and rice husk with different pyrolysis temperatures," BioResources, vol. 12, pp. 4652-4669, 2017.

[56] U. Kumar, S. Maroufi, R. Rajarao et al., "Cleaner production of iron by using waste macadamia biomass as a carbon resource," Journal of Cleaner Production, vol. 158, pp. 218-224, 2017.

[57] P. Fu, S. Hu, J. Xiang, L. Sun, S. Su, and J. Wang, "Evaluation of the porous structure development of chars from pyrolysis of rice straw: Effects of pyrolysis temperature and heating rate," Journal of Analytical and Applied Pyrolysis, vol. 98, pp. 177183, 2012.
[58] J. Anandkumar and B. Mandal, Journal of Hazardous Materials, vol. 168, pp. 633-640, 2009.

[59] M. R. R. Kooh, R. Thotagamuge, Y.-F. Chou Chau, A. H. Mahadi, and C. M. Lim, "Machine learning approaches to predict adsorption capacity of Azolla pinnata in the removal of methylene blue," Journal of the Taiwan Institute of Chemical Engineers, vol. 132, article 101134, 2022.

[60] I. Ghosh, S. Kar, T. Chatterjee, N. Bar, and S. K. Das, "Removal of methylene blue from aqueous solution using Lathyrus sativus husk: Adsorption study, MPR and ANN modelling," Process Safety and Environmental Protection, vol. 149, pp. 345-361, 2021.

[61] K. Ghosh, N. Bar, A. B. Biswas, and S. K. Das, "Removal of methylene blue (aq) using untreated and acid-treated eucalyptus leaves and GA-ANN modelling," The Canadian Journal of Chemical Engineering, vol. 97, pp. 2883-2898, 2019.

[62] T. Ahmed, W. Noor, O. Faruk, M. C. Bhoumick, and M. T. Uddin, "Removal of methylene blue (MB) from waste water by adsorption on jackfruit leaf powder (JLP) in continuously stirred tank reactor," Journal of Physics: Conference Series, vol. 1086, article 012012, 2018.

[63] M. Khodaie, N. Ghasemi, B. Moradi, and M. Rahimi, "Removal of Methylene Blue from Wastewater by Adsorption onto $\mathrm{ZnCl}_{2}$ Activated Corn Husk Carbon Equilibrium Studies," Journal of Chemistry, vol. 2013, Article ID 383985, 6 pages, 2013.

[64] M. R. R. Kooh, L. B. L. Lim, M. K. Dahri, L. H. Lim, and J. M. R. Sarath Bandara, "Azolla pinnata: an efficient low cost material for removal of methyl violet $2 \mathrm{~B}$ by using adsorption method," Waste and Biomass Valorization, vol. 6, pp. 547559, 2015.

[65] X. He, J. Jiang, Z. Hong, X. Pan, Y. Dong, and R. Xu, "Effect of aluminum modification of rice straw-based biochar on arsenate adsorption," Journal of Soils and Sediments, vol. 20, pp. 3073-3082, 2020.

[66] J.-H. Yuan, R.-K. Xu, and H. Zhang, "The forms of alkalis in the biochar produced from crop residues at different temperatures," Bioresource Technology, vol. 102, pp. 3488-3497, 2011.

[67] D. J. Patty, G. Loupatty, and F. Sopalauw, "Interpretation FTIR spectrum of seawater and sediment in the Ambon Bay (TAD)," AIP Conference Proceedings, vol. 1801, article 060005, 2017.

[68] A. A. Spagnoli, D. A. Giannakoudakis, and S. Bashkova, "Adsorption of methylene blue on cashew nut shell based carbons activated with zinc chloride: The role of surface and structural parameters," Journal of Molecular Liquids, vol. 229, pp. 465-471, 2017.

[69] Y. Hu, T. Guo, X. Ye et al., "Dye adsorption by resins: Effect of ionic strength on hydrophobic and electrostatic interactions," Chemical Engineering Journal, vol. 228, pp. 392-397, 2013.

[70] S. Bhattacharya, N. Bar, B. Rajbansi, and S. K. Das, "Adsorptive Elimination of $\mathrm{Cu}(\mathrm{II})$ from Aqueous Solution by Chitosan-nanoSiO ${ }_{2}$ Nanocomposite-Adsorption Study, MLR, and GA Modeling," Water, Air, \& Soil Pollution, vol. 232, no. 4, p. 161, 2021.

[71] M. R. R. Kooh, L. B. L. Lim, L. H. Lim, and J. M. R. S. Bandara, "Batch adsorption studies on the removal of malachite green from water by chemically modified Azolla pinnata," Desalination and Water Treatment, vol. 57, pp. 14632-14646, 2016. 